\title{
Bronchus Cartilage
}

National Cancer Institute

\section{Source}

National Cancer Institute. Bronchus Cartilage. NCI Thesaurus. Code C49209.

A hyaline cartilage in the form of irregular rings in the larger bronchi that changes to

small plates and islands in the smaller bronchi. 